\title{
Manipulation/Manual Therapy in the Treatment of Osteoarthritis
}

\section{Howard Vernon*}

Canadian Memorial Chiropractic College, Canada

Manual manipulation has a long history in the treatment of musculoskeletal pain [1]. Manipulation for the treatment of spinal pain conditions has become widely accepted as a result of numerous clinical trials, systematic reviews and clinical guidelines [2-4]. Surveys of chiropractic practice confirm that the vast majority of patients treated with manipulation present with MSK pain, and the majority of these present with spinal pain (back pain, neck pain) [5]. Manipulation for non-spinal or peripheral joints appears to be provided to a smaller proportion of patients. Accordingly, there has been less research in this area than in the area of spinal pain complaints.

In recent years, growing attention has been paid to sports-related injuries of the peripheral joints, and manipulation appears to be one of the accepted treatments for these types of acute or repetitive strain soft tissue injuries in mostly younger patients [6,7]. A different area of practice does, however, exist with respect to osteoarthritis in nonspinal joints experienced by patients in the later decades of life.

What is the status of the research on manipulation/manual therapy for osteoarthritis in the peripheral joints? A properly conducted systematic review would be necessary to give a definitive answer to this question; however, in this editorial, I will present a brief descriptive analysis of this evidence and I will attempt to provide an explanation of theories justifying the use of manipulation in osteoarthritis.

Manual manipulation is one of the types of therapies in the broader category of Manual Therapies. In its "professional clinical" form, it is currently practiced by chiropractors, osteopaths, physiotherapists and medical doctors ("manual medicine"). Within the broad category of manual therapy, manipulation sits at one pole of a spectrum of these therapies characterized by the magnitude of applied manual forces to the body tissues. Manipulation is characterized by high velocity, low amplitude manual thrusting procedures which aim to introduce motion to the joints. Mobilizations are performed without a thrusting component. At the other end of the spectrum, one would find low amplitude rubbing of the skin or the superficial muscles. This is characteristic of effleurage massage whose aim is to merely lightly stimulate these tissues.

The effects of manipulation-induced joint mobility include reduction of pain, reduction of muscle hyperactivity, induction of reflexes in the autonomic system, improvement in joint proprioception and, overall, an increase in joint mobility [8-13].

These effects constitute the aims of manipulation/manual therapy to the peripheral joints in clinical circumstances of acute or chronic (i.e., repetitive) strain and sprain of these joints as well as of chronic arthritic degeneration. The evidence base supporting the use of manipulation/ manual therapy for peripheral joint complaints is comprised of a small set of Randomized Clinical Trials (RCT's) as well as review papers and protocols for current or future studies, all of which can be identified by standard search methods in Pub Med and Google Scholar. A search current to December 2012 identified 20 trials [14-33], 15 for the knee [14-28], 3 for the hip [29-33], 1 for both hip and knee [34] and 1 for the hand [35] as well as four review papers [6,36-38] and 3 protocols for current or future studies [39-41].

\section{Knee Studies}

It should be stated at the outset that, when speaking of "manipulation" for knee OA, I am not referring to manipulation under anaesthesia in the context of surgical correction.

The vast majority of the knee studies are by Chinese authors. For five titles, it was not possible to obtain at least an abstract. Abstract or full papers were available for ten trials. Three of these trials used a manipulation-only group $[15,22,25]$. All three reported greater improvements in pain or stiffness or MRI-documented cartilage healing in the manipulation groups as compared to glucosamine sulphate [25], acupuncture [22] or control manual techniques [15].

In seven studies, manipulation was combined with acupuncture $[14,19]$, herbal therapy [17], moxibustion [20] or exercise $[24,26,27]$ Six reported greater improvement in the index group as compared to moxibustion alone [14], NSAID's [19] or glucosamine sulphate $[17,25]$, home exercise [26] and placebo ultrasound [27]. One study [24] reported equal and clinically important results between Tuina manipulation+exercise vs. Tuina manipulation alone. Deyle et al. [28] devised a clinical prediction rule for knee OA patients who were not likely to benefit from manual therapy+exercises: patella-femoral pain, anterior cruciate ligament laxity and height greater than $1.71 \mathrm{~m}$ Patients with at least 2 positive signs were $88 \%$ likely not to benefit from this treatment.

In one study, both knee and hip OA patients were included [34] This study investigated the use of osteopathic manipulative manual therapy (OMT) in patient's post-arthroplasty. None of the other studies included post-surgical cases. These authors found that OMT was no more effective than a sham therapy in these post-surgical cases.

\section{Hip Studies}

Three RCT's of manual therapy/manipulation were identified [29$31]$. In two of these $[30,31]$, manual therapy was compared to either a no-treatment control or to an exercise group. In the former case, chiropractic manipulation was superior to no treatment for pain relief over 3 weeks; in the latter case, manual therapy was superior to exercise therapy for pain and range of motion over 5 weeks of therapy including to a follow-up of 29 weeks. In the third trial [29], two modes of manual therapy (full kinetic chain vs. local hip) were compared along with exercises. This study found clinically important improvements in the WOMAC score for both groups, although neither group was superior to the other.

*Corresponding author: Howard Vernon, Canadian Memorial Chiropractic College 6100 Leslie Street, Toronto, Ontario, Canada M2H 3J1, E-mail: hvernon@cmcc.ca

Received January 16, 2013; Accepted January 16, 2013; Published January 22 2013

Citation: Vernon H (2013) Manipulation/Manual Therapy in the Treatment of Osteoarthritis. J Arthritis 2: e107. doi:10.4172/2167-7921.1000e107

Copyright: (c) 2013 Vernon H. This is an open-access article distributed unde the terms of the Creative Commons Attribution License, which permits unrestricted use, distribution, and reproduction in any medium, provided the original author and source are credited. 


\section{Hand Study}

The only RCT [35] for the hand compared mobilization of the thumb to sham mobilization in 28 OA patients over a 2-week, 4 session study. The manual therapy group showed greater reductions in local pressure tenderness, but not in motor functions.

The review articles cited above generally acknowledge the value of manipulation for knee and hip OA patients, especially in cases that are less severe and in need of surgical correction. One interesting study [41] reported on the use of complementary medicine, including manipulation and manual therapies in 2679 patients with knee OA. Almost half of the subjects had used some form of CAM therapy. These authors concluded that "CAM is commonly used to treat joint and arthritis pain among persons with knee OA. The extent to which these treatments are effective in managing symptoms and slowing disease progression, remains to be proven.

Lapane et al.'s conclusion is quite appropriate for this editorial as a whole [41]. The current evidence base is encouraging of the notion that manipulation/manual therapy is helpful in osteoarthritis patients. It is also encouraging to see new and more sophisticated studies being planned in the protocols cited above. Hopefully, this will lead to greater acceptance and utilization of this form of therapy in osteoarthritis patients.

\section{References}

1. Wiese G, Callender A (2005) History of spinal manipulation. In: Haldeman S., ed. Principles and Practice of Chiropractic. New York, NY: McGraw Hill, 5-22.

2. Bronfort G, Haas M, Evans R, Leininger B, Triano J (2010) Effectiveness of manual therapies: the UK evidence report. Chiropr Osteopat 18: 3.

3. van Tulder M, Becker A, Bekkering T, Breen A, del Real MT, et al. (2006) Chapter 3. European guidelines for the management of acute nonspecific low back pain in primary care. Eur Spine J 15: S169-S191.

4. Bronfort G, Haas M, Evans R, Kawchuk G, Dagenais S (2008) Evidenceinformed management of chronic low back pain with spinal manipulation and mobilization. Spine J 8: 213-225.

5. Blum C, Globe G, Terre L, Mirtz TA, Greene L, et al. (2008) Multinational survey of chiropractic patients: reasons for seeking care. J Can Chiropr Assoc 52: $175-184$

6. Brantingham JW, Bonnefin D, Perle SM, Cassa TK, Globe G, et al. (2012) Manipulative therapy for lower extremity conditions: update of a literature review. J Manipulative Physiol Ther 35: 127-166.

7. Brantingham JW, Cassa TK, Bonnefin D, Jensen M, Globe G, et al. (2011) Manipulative therapy for shoulder pain and disorders: expansion of a systematic review. J Manipulative Physiol Ther 34: 314-346.

8. Triano J (2005) The theoretical basis for spinal manipulation. In: Haldeman S, ed. Principles and Practice of Chiropractic. New York, NY: McGraw Hill, 361382.

9. Millan M, Leboeuf-Yde C, Budgell B, Descarreaux M, Amorim MA (2012) The effect of spinal manipulative therapy on spinal range of motion: a systematic literature review. Chiropr Man Therap 20: 23.

10. Hegedus EJ, Goode A, Butler RJ, Slaven E (2011) The neurophysiological effects of a single session of spinal joint mobilization: does the effect last? Man Manip Ther 19: 143-151.

11. Henderson CN (2012) The basis for spinal manipulation: chiropractic perspective of indications and theory. J Electromyogr Kinesiol 22: 632-642.

12. Haavik H, Murphy B (2012) The role of spinal manipulation in addressing disordered sensorimotor integration and altered motor control. J Electromyogr Kinesiol 22: 768-776.

13. Pickar JG, Bolton PS (2012) Spinal manipulative therapy and somatosensory activation. J Electromyogr Kinesiol 22: 785-794.

14. Sun K, Bao XM, Song YC, Liu DC (2010) Clinical study on the treatment of knee osteoarthritis by acupuncture plus manipulative regulation of knee muscle. Zhongguo Gu Shang 23: 895-898.

15. Moss P, Sluka K, Wright A (2007) The initial effects of knee joint mobilization on osteoarthritic hyperalgesia. Man Ther 12: 109-118.

16. Zhan W, Lin J, Li Z (2004) A clinical study on the joint mobilization with TCMmanipulation therapy for knee joint osteoarthritis. Chin J Rehabil Med.

17. Xu JW, Ding JZ (2005) An Analysis on the Clinical Therapeutic Effect Of the Manipulation Matched with Chinese Medical Herb Washing for Treatment of Osteoarthritis of the Knee. J Beijing Teachers Coll Phys Educ.

18. Guo D, Cao XW, SJ Xu, Pan JK, Liu J (2012) Shishi manipulation for knee osteoarthritis: a randomized, controlled trial.

19. Yao Z, Zhang J, Wang C (2007) Clinical Effectiveness of Acupotome and Manipulation in the Treatment of Knee Osteoarthritis and Its Effect on Plasma Metabolism of Oxygen Free Radicals. Chin J Rehabil.

20. Su J, Cao L, Chen W, Wang S, Ma Y, et al. (2009) Observation on therapeutic effect of moxibustion combined with manipulation-therapy on knee osteoarthritis. J Tongji.

21. Huang W, Zhang G, Jian S (2011) Analysis of influencing the survival quality of manipulation on patients with knee osteoarthritis. Mod Hosp.

22. Ye QH, Zhu JW, Wu JX, Zhu WN (2011) Comparison of the clinical effects between acupuncture and manipulation in knee osteoarthritis. J Practical Med 2010-11.

23. Yang J, He MJ (2012) Treatment of knee osteoarthritis with manipulation Zhongguo Gu Shang 25: 411-412.

24. Wang JL, Chai CH, Xu YM (2008) Clinical observations on the effect of Tuigua manipulation combined with quadriceps exercise for the treatment of degenerative gonarthritis. Zhongguo Gu Shang 21: 887-889.

25. Du N, Lu Y, Gu X, Hu J (2008) Magnetic resonance assessment the effect of manipulation on knee cartilaginous recovery of osteoarthritis. Zhongguo $\mathrm{Gu}$ Shang 21: 824-827.

26. Deyle GD, Allison SC, Matekel RL, Ryder MG, Stang JM, et al. (2005) Physical therapy treatment effectiveness for osteoarthritis of the knee: a randomized comparison of supervised clinical exercise and manual therapy procedures versus a home exercise program. Phys Ther 85: 1301-1317.

27. Deyle GD, Henderson NE, Matekel RL, Ryder MG, Garber MB, et al. (2000) Effectiveness of manual physical therapy and exercise in osteoarthritis of the knee. A randomized, controlled trial. Ann Intern Med 132: 173-181.

28. Deyle GD, Gill NW, Allison SC, Hando BR, Rochino DA (2012) Knee OA: which patients are unlikely to benefit from manual PT and exercise? J Fam Pract 61 E1-E8.

29. Brantingham JW, Parkin-Smith G, Cassa TK, Globe GA, Globe D, et al. (2012) Full kinetic chain manual and manipulative therapy plus exercise compared with targeted manual and manipulative therapy plus exercise for symptomatic osteoarthritis of the hip: a randomized controlled trial. Arch Phys Med Rehabil 93: 259-267.

30. Thorman P, Dixner A, Sundberg T (2010) Effects of chiropractic care on pain and function in patients with hip osteoarthritis waiting for arthroplasty: a clinical pilot trial. J Manipulative Physiol Ther 33: 438-444.

31. Hoeksma HL, Dekker J, Ronday HK, Heering A, van der Lubbe N, et al. (2004) Comparison of manual therapy and exercise therapy in osteoarthritis of the hip: a randomized clinical trial. Arthritis Rheum 51: 722-729.

32. Hoeksma HL, Dekker J, Ronday HK, Breedveld FC, Van den Ende CH (2005) Manual therapy in osteoarthritis of the hip: outcome in subgroups of patients. Rheumatology (Oxford) 44: 461-464.

33. Hoeksma HL, van den Ende CH, Breedveld FC, Ronday HK, Dekker J (2005) A comparison of the OARSI response criteria with patient's global assessment in patients with osteoarthritis of the hip treated with a non-pharmacological intervention. Osteoarthr Cart 14: 77-81.

34. Licciardone JC, Stoll ST, Cardarelli KM, Gamber RG, Swift JN Jr, et al. (2004) A randomized controlled trial of osteopathic manipulative treatment following knee or hip arthroplasty. J Am Osteopath Assoc 104: 193-202.

35. Villafañe JH, Silva GB, Fernandez-Carnero J (2012) Effect of thumb joint mobilization on pressure pain threshold in elderly patients with thumb carpometacarpal osteoarthritis. J Manipulative Physiol Ther 35: 110-120. 
36. Iversen MD (2012) Rehabilitation interventions for pain and disability in osteoarthritis: a review of interventions including exercise, manual techniques, and assistive devices. Orthop Nurs 31: 103-108.

37. Brantingham JW, Globe G, Pollard H, Hicks M, Korporaal C, et al. (2009) Manipulative therapy for lower extremity conditions: expansion of literature review. J Manipulative Physiol Ther 32: 53-71.

38. Abbott JH, Robertson MC, McKenzie JE, Baxter GD, Theis JC, et al. (2009) Exercise therapy, manual therapy, or both, for osteoarthritis of the hip or knee: a factorial randomised controlled trial protocol. Trials 10: 11
39. Poulsen E, Christensen HW, Roos EM, Vach W, Overgaard S, et al. (2011) Nonsurgical treatment of hip osteoarthritis. Hip school, with or without the addition of manual therapy, in comparison to a minimal control intervention: protoco for a three-armed randomized clinical trial. BMC Musculoskelet Disord 12: 88.

40. French HP, Cusack T, Brennan A, White B, Gilsenan C, et al. (2009) Exercise and manual physiotherapy arthritis research trial (EMPART): a multicentre randomised controlled trial. BMC Musculoskelet Disord 10: 9.

41. Lapane KL, Sands MR, Yang S, McAlindon TE, Eaton CB (2012) Use of complementary and alternative medicine among patients with radiographicconfirmed knee osteoarthritis. Osteoarthritis Cartilage 20: 22-28. 